\section{Instability in the normal CTG repeat range at the myotonic dystrophy locus}

We present a family clinically unaffected by dystrophia myotonica (DM), in whom molecular studies detected different CTG repeat numbers in sibs of one generation and also remarkable CTG repeat instability in two consecutive generations in the range of $<50$ CTG copies. In our family, paternal transmission (father 37 repeats, son 48 repeats) resulted in a maximum increase of 11 CTG repeats in the next generation. This increase has not previously been observed in unaffected families. The intergenerational unstable CTG repeats showed no somatic mosaicism in blood lymphocytes. CTG repeat numbers were defined by polymerase chain reaction (PCR) and a refined Southern protocol.

The CTG repeat region in the $3^{\prime}$ untranslated region of the DMPK gene on 19q13.2-3 is highly variable in DM patients and also in unaffected probands. In the normal population the CTG repeat alleles are stably inherited. Because of our interest in CTG repeat allele frequencies at multiple loci, including the DM locus, in the German population we have asked families to participate in molecular testing. Here we report the results of an eight member, three generation family (fig 1A). Blood samples from subjects I. 2 and III. 1 were not available. All other family members donated peripheral blood for the investigation after informed consent. No signs of DM were found in the family members after a thorough neurologica examination, ' nor were there any indications of genetically determined disorders. Subject I. 2 had died of lung oedema at 65 years. $\mathrm{He}$ had no symptoms of DM.

PCR analyses were performed with primers 101 and $102,{ }^{2}$ which flank the DM repeat PCR products were separated on a $10 \%$ polyacrylamide gel and visualised by ethidium bromide staining on an UV transilluminator. Automatic fragment length analysis of $5^{\prime} \mathrm{Cy} 5^{\mathrm{TM}}$ fluorescently labelled PCR products was performed on ALF (ALF Express ${ }^{\mathrm{TM}}$ Personal DNA Sequencer, Pharmacia BioTech) using commercially available external size markers (Pharmacia BioTech) and an internal length standard (PCR product of the probe p5B1.4 containing five CTG repeats). Fragment sizes were calculated with fragment manager software package (Pharmacia BioTech). For Southern blot analyses we used $E c o$ RI, $B g I$, $B a m H I$, and radiolabelled probe p5B1.4. ${ }^{2}$ Paternity was tested by fingerprinting.

CTG repeat numbers are shown in the pedigree (fig 1A). CTG repeat sizes were confirmed by automatic analysis of the PCR products, except for the repeat number size of the grandmother (I.1). By ALF analysis, the grandmother had 11 and 12 CTG copies. Al family members of generation II had one allele with 12 CTG repeats and another allele with different CTG copy numbers: $20 \times$ CTG (II.1), $39 \times$ CTG (II.2), and $37 \times$ CTG (II.3). The mother (II.4) of the child III.2 had two different common alleles: $5 \times$ CTG and $13 \times$ CTG. The child (III.2) had 5 and 48 CTG repeats (fig $1 \mathrm{~A}$ ).

To the best of our knowledge this is the firs description of unstable transmission of CTG repeats to all unaffected sibs from the same parents. All members of generation II had more than 19 CTG repeats on this second allele. Additionally, we showed an increase of CTG copies in the third generation (III.2) at the same time. The unstable paternal transmission from father (II.3) to son (III.2) resulted in a maximum increase of 11 CTG copies. This CTG increase is distinctly smaller than usually seen in families with $D M$ heterozygotes.

Large CTG repeats (>42 CTG repeats) are predisposed to instability ${ }^{34}$ and the grandchild III.2 is in this range. This fact is

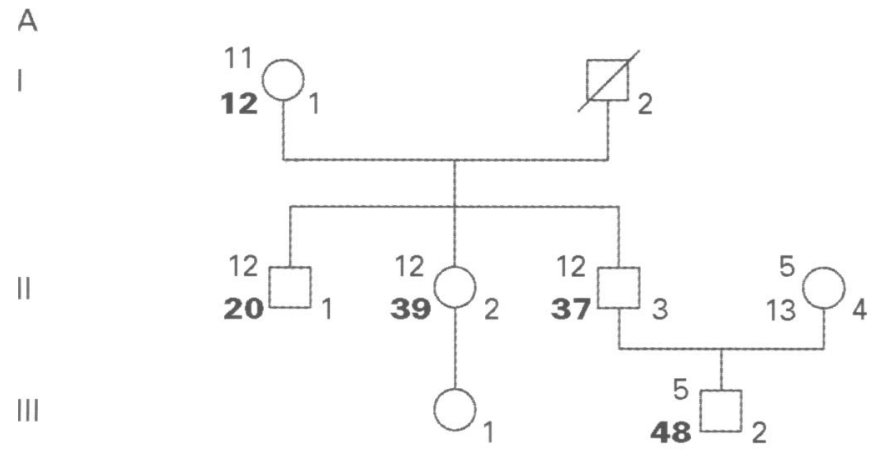

B

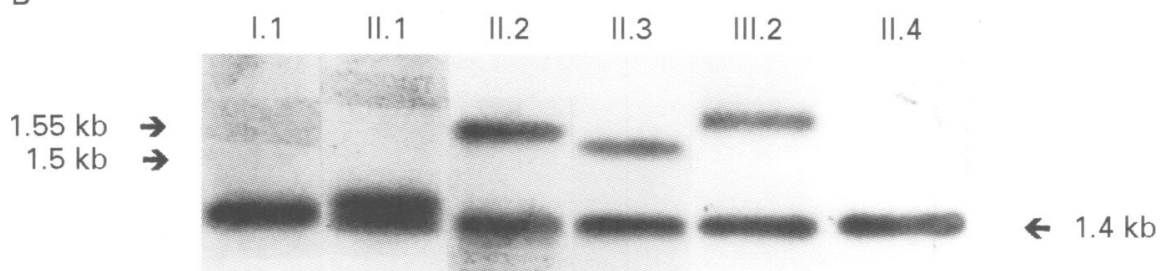

Figure 1 (A) Family pedigree. Numbers of CTG repeats on both alleles are shown. DNA from subjects I.2 and III.1 was not investigated. (B) Restriction fragment length patterns of high resolution Southern blot analysis with endonuclease BamHI detected with DNA probe p5B1.4 in the family members. BamHI fragments were not separated on the same blot but they are of comparable resolution indicated by the PCR products. very important for genetic counselling. Whether further repeat expansion will occur on transmission to the next generation followed by the expression of the DM phenotype, remains to be seen. We are currently trying to identify additional family members such as sibs and cousins of I.2 from this pedigree. Longitudinal clinical and molecular studies of probands with critical CTG repeat numbers will be required.

We are grateful to Dr Helmut Dalitz, Leipzig, for the blood probes. Dr Meiner was supported by a grant from the "Studienstiftung des Deutschen Volkes".

A MEINER B THAMM S STRENGE U FROSTER

Institut für Humangenetik, Universität Leipzig, Philipp-Rosenthal-Strasse 55, 04103 Leipzig, Germany

1 Griggs RC, Wood DS, and the Working Group on the Molecular Defect in Myotonic Dystrophy. Criteria for establishment of the validity of genetic recombination in myotonic dystrophy. Neurology 1989;39:420-1.

2 Brook JD, McCurrach ME, Harley HG, et al. Molecular basis of myotonic dystrophy: expansion of a trinucleotide (CTG) repeat at the $3^{\prime}$ end of a transcript encoding a protein kinase family member. Cell 1992;68:799-808.

3 Imbert G, Kretz C, Johnson K, Mandel JL. Oriin of the expansion mutation in myotonic dystrophy. Nat Genet 1993;4:72-4

4 Jansen G, Willems P, Coerwinkel M, et al. Gonosomal mosaicism in myotonic dystrophy patients: involvement of mitotic events in (CTG)n repeat variation and selection against extreme expansion in sperm. Am $f$ Hum Genet 1994;54:575-85.

\section{BOOK REVIEWS}

If you wish to order or require further information regarding the titles reviewed here, please write to or telephone the BMJ Bookshop, PO Box 295, London WC1H 9JR. Tel 01713836244 . Fax 01713836662. Books are supplied post free in the UK and for BFPO addresses. Overseas customers should add $15 \%$ for postage and packing. Payment can be made by cheque in sterling drawn on a UK bank or by credit card (Mastercard, Visa, or American Express) stating card number, expiry date, and full name. (The price and availability are occasionally subject to revision by the Publishers.)

Gene Transfer in the Cardiovascular System: Experimental Approaches and Therapeutic Implications. Editor Keith L March. (£119.50.) Dordrecht, The Netherlands: Kluwer Academic Publishers Group. 1997. ISBN 0792398599.

Keith March has coordinated contributions from many established investigators in the rapidly expanding field of cardiovascular gene transfer to produce a comprehensive and up to date volume.

The book is divided into several sections, each comprising several chapters and dealing with one broad aspect of cardiovascular gene transfer. The first and largest section deals with aspects of vector systems and gives thorough accounts of retrovirus vectors, adenovirus vectors including newer "second generation" vectors, liposome mediated gene 